\title{
Origin of TPHs and PAHs in the marine sediment nearby oil and gas extraction sites on the west coast of Qatar
}

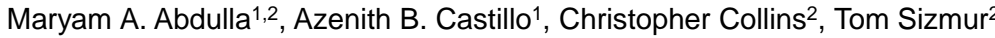

${ }^{1}$ Environmental Science Center, Qatar University, P.O. Box 2713, Qatar

${ }^{2}$ Department of Geography and Environmental Science, University of Reading, P.O. Box 217, United Kingdom

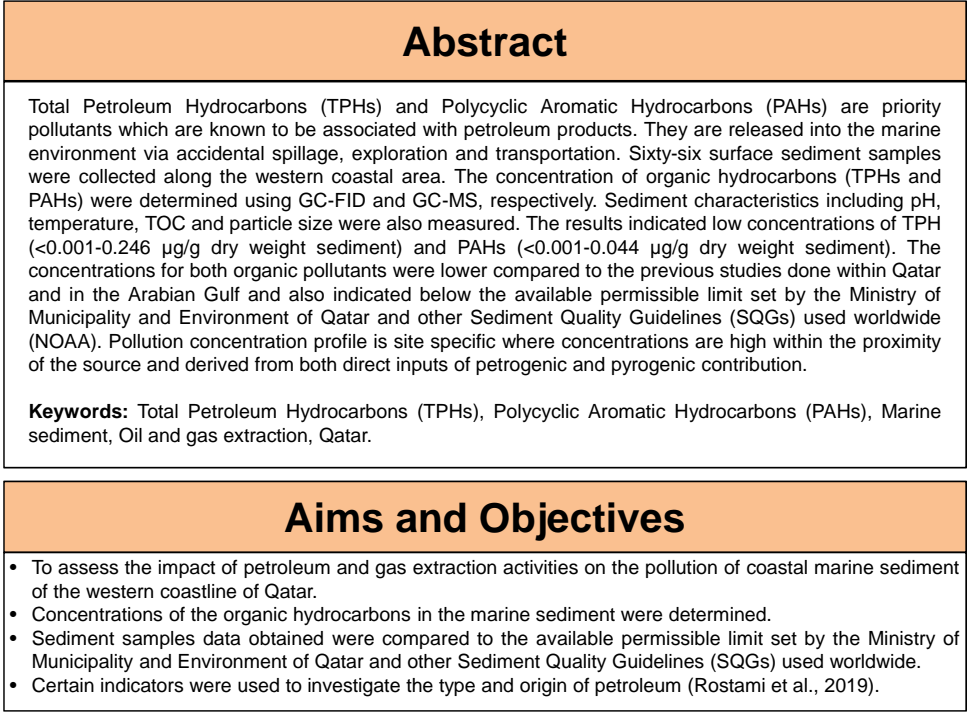

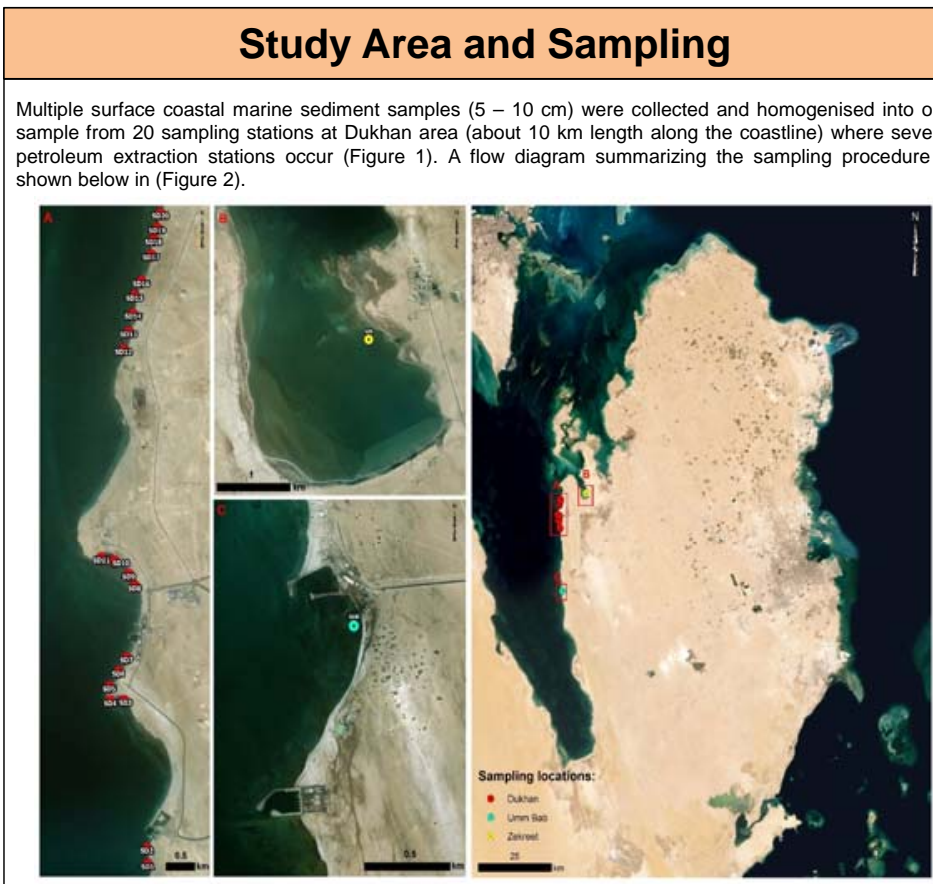

Figure 1. Map of Qater showing the sediment sampling stations at three locations: Dukhan, Zekreet and Umm Bab. Base map: WorldView-2 satellite data acquired in November 2011 by DigitalGlobe, Inc (Esri).

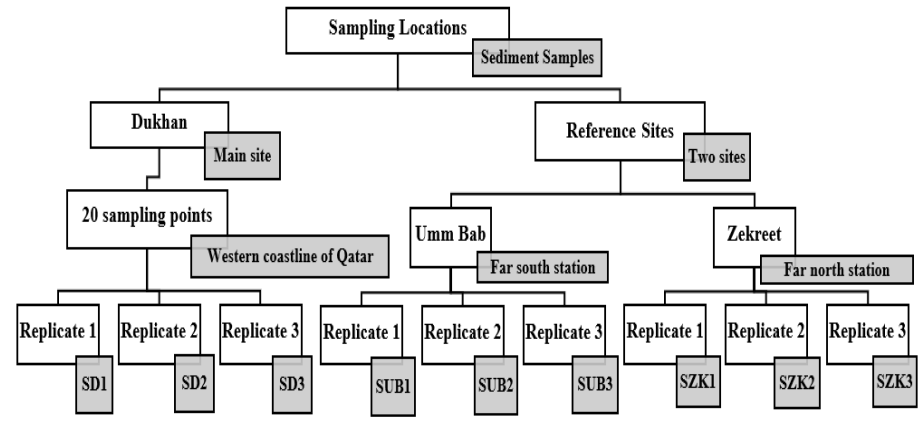

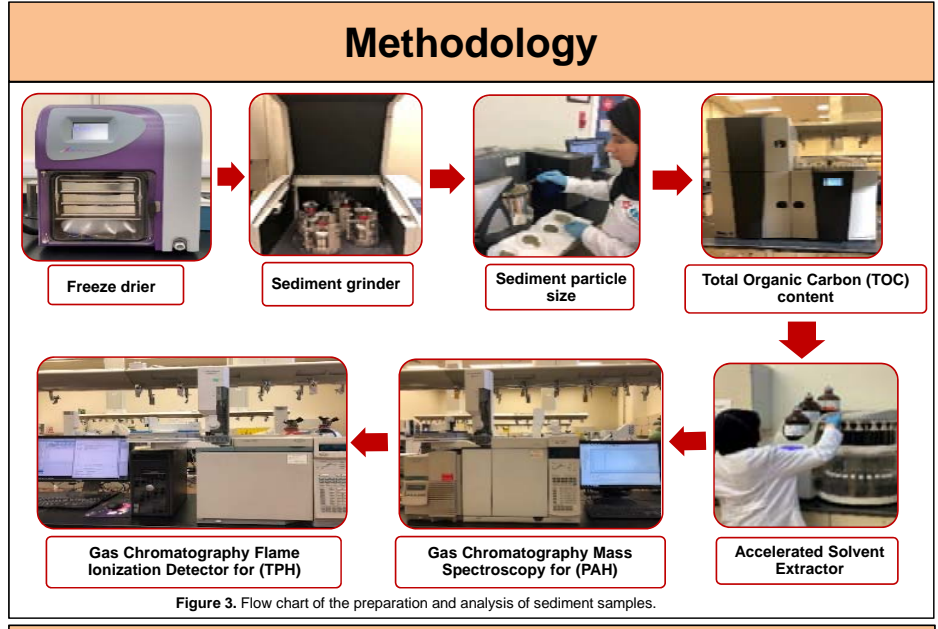

\section{Results and Discussion}

Origin of petroleum hydrocarbon

In the presence of fresh crude oil, the ratio of the concentration of total $\mathrm{n}$-alkanes of LMW (C10 $\mathrm{C} 18)$ to the concentration of $\mathrm{n}$-alkanes of $\mathrm{HMW}$ (C20 - C32) are used as indicator (Gearing et al., 1976; Rostami et al., 2019).

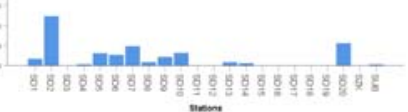
(<LOD, refer to Figure 4) were obtained in ( almost all the sites studied that calculating for is not feasible. The low levels could be attributed to the weathering of the aliphatic (n-alkanes) components of the petroleum crude oil.

Figure 4. Mean total petroleum hydrocarbon concentrations in
sediment samples of sediment samples of Qatar western coastline compared with
local guidelines. Pyrogenic processes e.g., combustion of oil, coal, and wood, pyrolysis or natural fires, and industrial combustion activities, produce mainly high molecular weight (HMW) PAHs and nonalkylated PAHs (Law et al. 1994, Baumard et al. 1998) Therefore the ratio between the LMW compounds (2-3 rings) and HMW Compounds (4-6 rings) can be used also as an indicauds (4-6 ings) can be used also as an indicator to differentiate petrogenic from pyrogenic PAHs

Source.
The ratio of LMW/HMW PAHs $<1$ indicates sediment pollution is by pyrolytic inputs while LMW/HMW PAHs $>1$ represents petrogenic source of pollution.

Figure 5. Mean total polycyclic aromatic hydrocarbon compared with international guidelines.

Concentration of sediment TPH and PAH Many factors might contribute to the decrease of hydrocarbons concentrations such as the enforcement of regulations and the use of advanced technology that is more environmentally friendy during different production (Lang et al., 2007).

production (Lang concentrations of hydrocarbons observed in the present study is likely related to an increase in sediments temperature.

This mainly contributes to volatilization, degradation and solubility of low molecular weight PAHs such as acenaphthylenes and naphthalenes by disturbing the partitioning of
the PAHs between organic and aquatic phases (Cui et al., 2016).

\section{Conclusion}

- According to the results obtained from the present study, it can be concluded that oil and gas extraction activities along the western coastline of Qatar did not have a direct impact on the marine sediments to the extent that environmental quality standards are exceeded.

- Further studies would be beneficial to investigate the atmospheric deposition of these petroleum hydrocarbon contaminants and their levels in the marine waters especially in this part of the country to compare and evaluate their contributory levels to environmental pollution.

\section{References}

